\title{
Pedestrian and bicycle bridges as examples of safe collision-free road crossings
}

\author{
Mikołaj Miśkiewicz ${ }^{1 *}$, Lukasz Pyrzowski ${ }^{1}$, and Romanika Okraszewska ${ }^{1}$ \\ ${ }^{1}$ Gdansk University of Technology, Faculty of Civil and Environmental Engineering, Gdansk, Poland
}

\begin{abstract}
Pedestrians are most at risk when they are crossing the road. This represents a significant proportion of all fatalities among pedestrians, amounting respectively to $50 \%$ in non-built-up areas and $75 \%$ in built-up areas. The most frequent reason for this accident is failure to give way. What is most terrible is that $30 \%$ of pedestrian accidents occurred at marked pedestrian crossings. Therefore, an important part of pedestrian safety management is selecting the right type of crossings, which are suitable for the conditions. At certain speeds and traffic volume, the only safe option for pedestrian crossings is to apply multi-level solutions, that is footbridges or tunnels. The paper presents examples of infrastructure redesign by constructing footbridges and hence, separating pedestrians and vehicular traffic to improve pedestrian safety.
\end{abstract}

\section{Introduction and regulations}

A European Transport Safety Council report published in June 2016 [1] points out to Poland as a country in which the number of road deaths per travelled vehicle-distance is the highest in the European Union. In 2015, 26\% of all car accidents involved pedestrians and 14\% involved cyclists. Hitting a pedestrian is the most tragic kind of accident on Polish roads. $31.4 \%$ of fatalities are pedestrians. The largest number of pedestrian and cyclist accidents occurs in urban areas, however, the consequences of accidents which happen outside builtup areas are more tragic. More details about the situation on Polish roads may be found in the report of the Polish Traffic Police Service [2]. This statistic shows that with such poor safety of vulnerable road users, it is imperative that programmes and actions are developed to protect pedestrians and cyclists.

Pedestrians are most at risk when they are crossing the road. This represents a significant proportion of all fatalities among pedestrians, amounting respectively to $50 \%$ in non-builtup areas and $75 \%$ in built-up areas. The most frequent reason for this kind of accidents is failure to give way. What is most terrible is that $30 \%$ of pedestrian accidents occurred at marked pedestrian crossings (see Fig. 1) [3]. Therefore, an important part of pedestrian safety management is selecting the right type of crossings, which are suitable for the conditions. According to Polish law, pedestrians are allowed to cross the road as follows:

- in any place, if far from the designated pedestrian crossing (the distance to the nearest crossing should be longer than that required by road traffic law),

\footnotetext{
* Corresponding author: mmisk@pg.gda.pl
} 
- at-grade pedestrian crossings (with or without traffic lights; with an "island"; with barriers defining a path for pedestrians),

- collision-free grade-separated crossings in the form of a footbridge or tunnel.

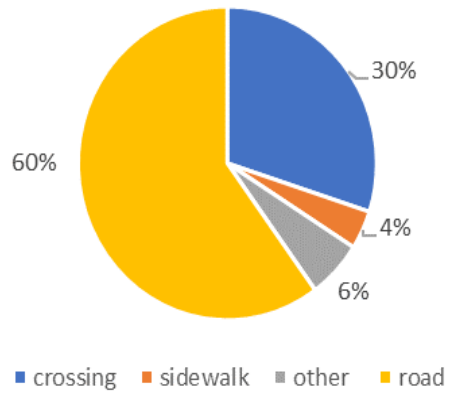

Fig. 1. Distribution of accidents with pedestrians on Poland's road network. Source: own study based on [3].

Pedestrians and cyclists prefer to use at-grade crossings. This is because the distance is shorter and there is no difference in elevation. However, in some cases, to ensure road user safety, grade-separated crossings are indispensable. Tunnels and footbridges should be used as collision-free crossings when:

- pedestrian routes intersect with higher class roads,

- pedestrian routes intersect with the roads of G (main road) or GP (major trunk road) class with heavy traffic,

- the location of an at-grade pedestrian crossing may pose a serious hazard to pedestrians or cause long delays for vehicles and pedestrians [3].

The right choice of pedestrian crossing must be preceded with an analysis of behavioural aspects of pedestrians. Studies show that, if the implementation of a grade-separated crossing extends the distance to be covered by pedestrians by $50 \%$ or more, pedestrians will try and cross the roadway despite the prohibitions [3]. Therefore, where possible, at-grade crossings should remain. However, as we can see from the nomogram in Fig. 2, for certain speeds and traffic volumes, grade-separated solutions such as footbridges or tunnels are the only safe option. This solution should be additionally supported with physical barriers to stop pedestrians from using prohibited at-grade crossings.

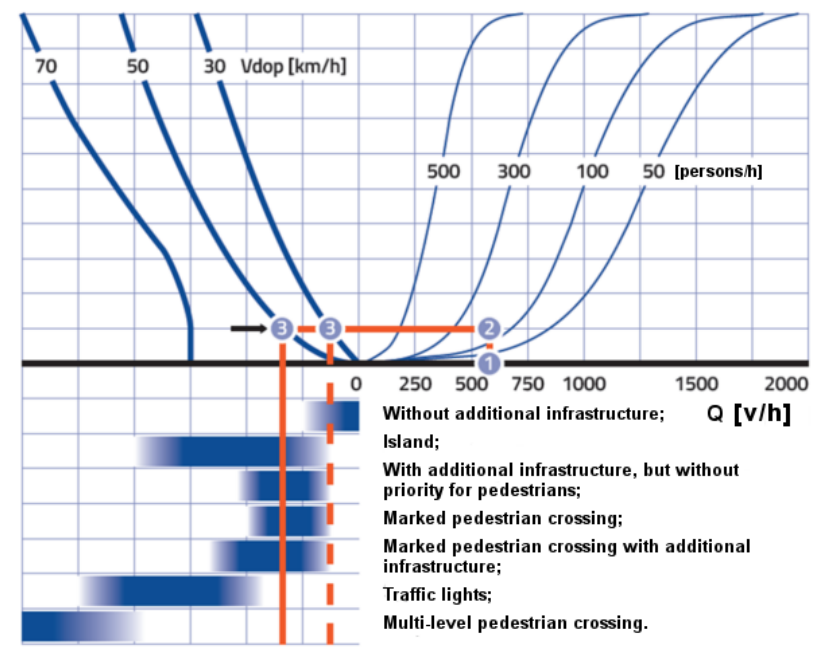

Fig. 2. Selection of the type of pedestrian crossings in urban areas. Source [3]. 


\section{Design conditions for footbridges}

The most popular static schemes applied in footbridges are beam, arch and cable-stayed structures. They should be characterized by a low value of the structural height parameter, due to the fact that many of them are built above the roads. The span length of footbridges is determined by obstacles. In the case of road crossings, the main parameter is road clearance. It depends on the road class given in national alignments[4]. For example, in Polish regulations for GP ${ }^{i}$ class roads the minimum value of a traffic lane is $3.5 \mathrm{~m}$, shoulder $0.5 \mathrm{~m}$ and verge $1.5 \mathrm{~m}$. The usable width of footbridge decks is also regulated. Bidirectional decks for pedestrians should have the minimum width of $1.5 \mathrm{~m}$ and $2.0 \mathrm{~m}$ for cyclists. The structures in Poland must comply with the regulations given in [4] and [5].

\section{Case studies}

\subsection{Footbridge in Męcikał}

The first example of a footbridge which saves human lives is the footbridge in Męcikał over the Brda river (Fig. 3). The structure was built in 2010, the details may be found in [6]. The footbridge was built in response to the needs of local residents. It connects two places which are periodically visited by a significant number of people - a school and church. Before the new route was opened, people and cyclists were forced to use the narrow walkways on the bridge, along the road No. 235. The new footbridge is not only for the convenience of pedestrians but for their safety as well, because as we can see in Fig. $14 \%$ of all accidents with pedestrians occur on sidewalks. The steel arch structure with a span of $42 \mathrm{~m}$ and full length of $58.46 \mathrm{~m}$, improved safety of local pedestrians and cyclists, especially children walking to school.

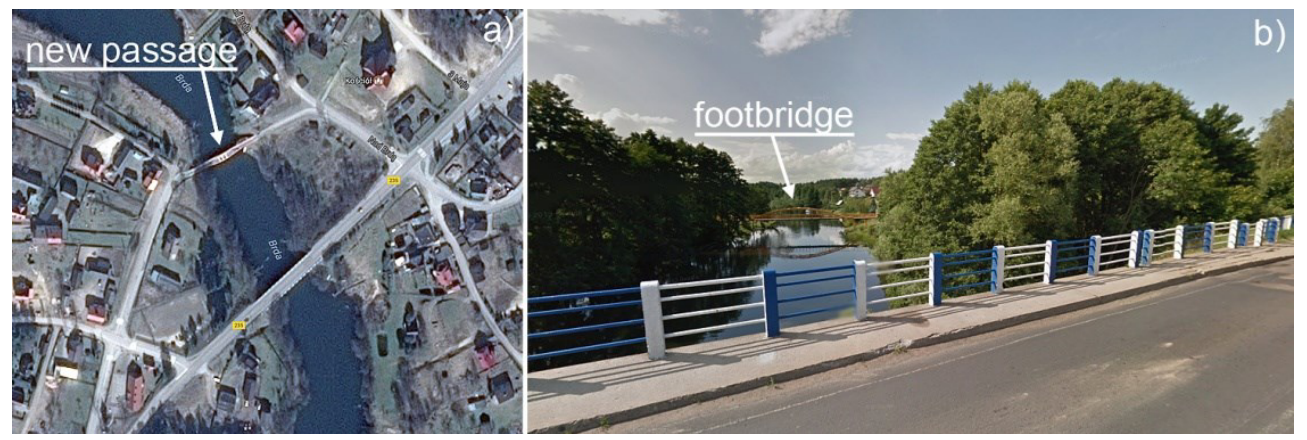

Fig. 3. Footbridge in Męcikał: a) location, b) view from the road No. 235. Source: www.google.pl/maps.

\subsection{Footbridge in Rzeszów along Piłsudskiego avenue}

The footbridge in Rzeszów was built in 2012 over a junction of $Z$ class road - Piłsudskiego avenue and L class road Grunwaldzka street (Fig. 4). The structure was erected to solve traffic problems in one of the busiest places in the city centre. This is an example where an at-grade pedestrian crossing is not a good solution due to heavy traffic. Crossing over the road was chosen over crossing under the road because of the extensive underground infrastructure and the enormous cost of the tunnel. The footbridge separates pedestrians and vehicular traffic. To ensure pedestrian access to the footbridge from every side and free movement in any direction, the round shape was proposed. The ring has a diameter of about $40 \mathrm{~m}$ and is divided 
into four spans, for details see [7]. The unusual shape of the footbridge makes it one of the few of this type in the world.

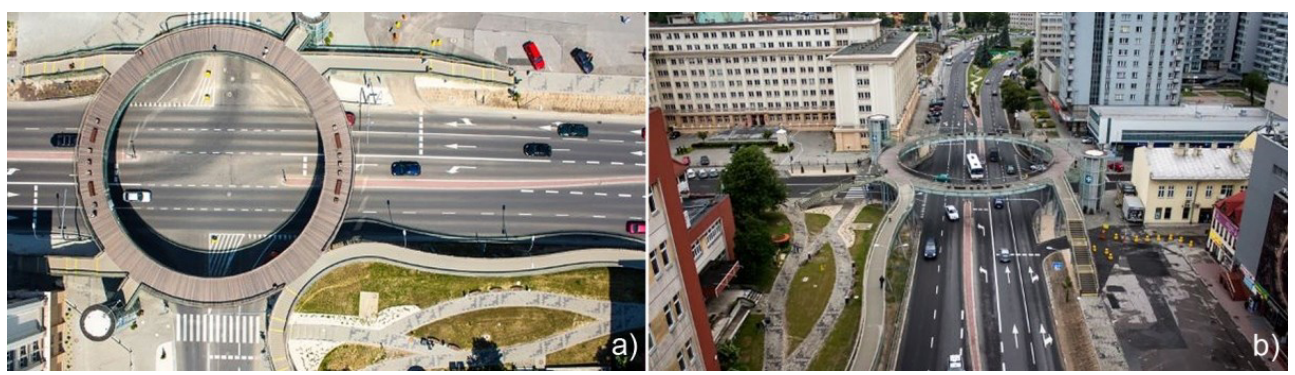

Fig. 4. Footbridge in Rzeszów on Piłsudskiego avenue. Source: www.skanska.pl.

\subsection{Overpass for cyclists in Gdynia}

The overpass for cyclists in Gdynia was opened in 2013 (Fig. 5). It is a multi-span steel structure of $301 \mathrm{~m}$ total length. It connects two streets Kontenerowa and Unruga. Cyclists may use this overpass to move along Kwiatkowskiego street where cycling is forbidden due to heavy traffic with a speed limit of $70 \mathrm{~km} / \mathrm{h}$. This calls for a segregation of cycle and motor traffic due to traffic volume.

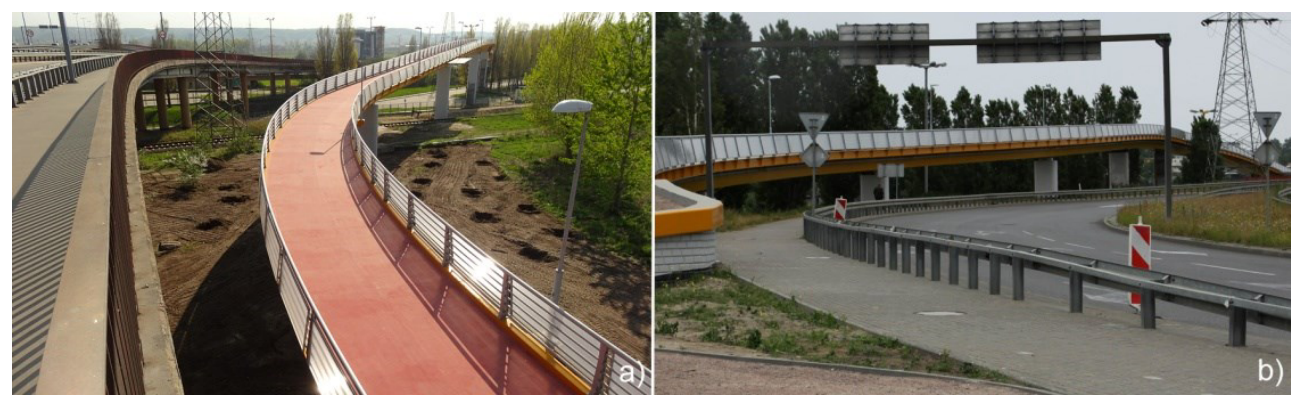

Fig. 5. Overpass for cyclists in Gdynia.

\subsection{Footbridge in Warsaw over S8 express road}

An example of a pedestrian crossing over a higher class road (expressway) is the footbridge in Warsaw (Fig. 6). This is an example of an engineering structure where the design plays an important aesthetic role rather than mechanical principles. This structure is composed in acoustic screen tunnels and allows grade-separated pedestrian traffic between two districts of Ruda and Potok. The construction was finished in 2015. The footbridge is a steel double span arch with a composite concrete-steel deck. Its main dimensions are 21.95 $+17.85 \mathrm{~m}$ span length in the support axis and $6.36 \mathrm{~m}$ width [8] 


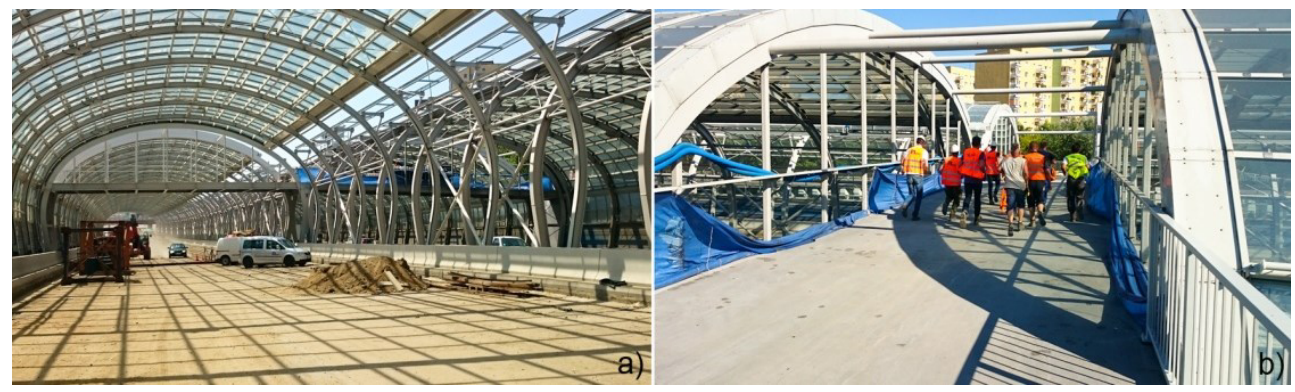

Fig. 6. Footbridge in Warsaw over S8 express road during load test.

\subsection{Suspension footbridge in Radom over Szarych Szeregów street}

The footbridge in Radom links two sides of the Obozowisko district divided by a dual carriageway of Szarych Szeregów and provides access to a catholic parish church (Fig. 7). It replaces the traditional pedestrian crossing on a heavy traffic road. The structure's basic dimensions are: span of $40.2 \mathrm{~m}$ and $4.5 \mathrm{~m}$ width. The footbridge is a suspended structure with an interesting architectural form. The steel-concrete composite deck is suspended on one rope and hangers to two concrete towers.

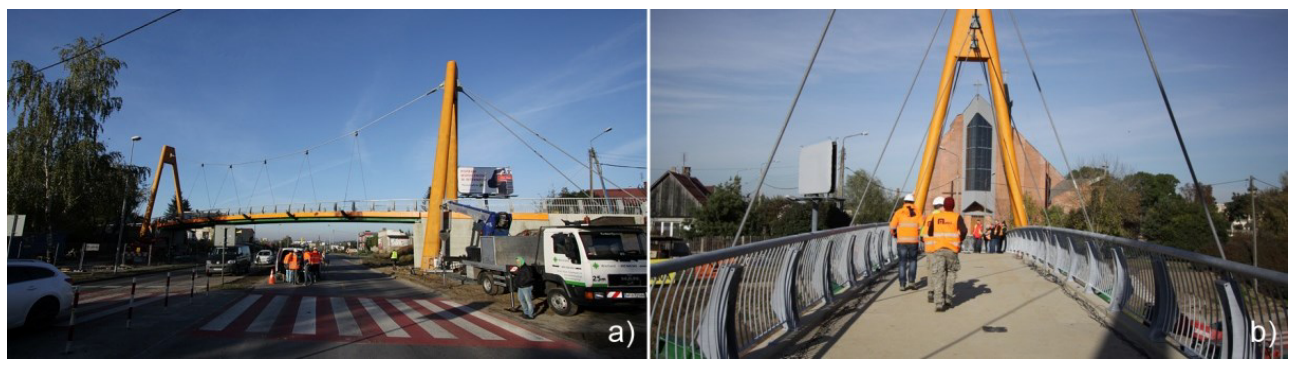

Fig. 7. Suspension footbridge in Radom over Szarych Szeregów street.

\subsection{GFRP composite footbridge}

The last example can make a real revolution, when it comes to the availability of cheap and fast to assemble structures, which in a very easy way may significantly increase the safety of vulnerable road users. The fully polymer composite footbridge presented in Fig. 8 was constructed by the Fobridge consortium in 2015, as a research object [9][10][11]. Numerous analyses and tests confirmed that this novel structure can be applied over roads. This single span footbridge length can be up to $22 \mathrm{~m}$ long. The span was tested at the Gdansk University of Technology at $14 \mathrm{~m}$. It is enough to cross a dual carriageway. The structure is durable, dynamically resistant, incombustible, easy to install and maintain, resistant to weather conditions and also aesthetically interesting. To produce the footbridge, the environmentally friendly PET foam core can be used. It may be sourced from recycled plastic packages and produced with lower energy consumption and much less $\mathrm{CO}_{2}$ emissions. It is a very attractive proposal for applications over roads and obstacles. Additionally, its very short production time and lightness, speed up the construction. As you can see in Fig. 9, the proposed footbridge ensures that a road with up to three lanes can be crossed safely. 


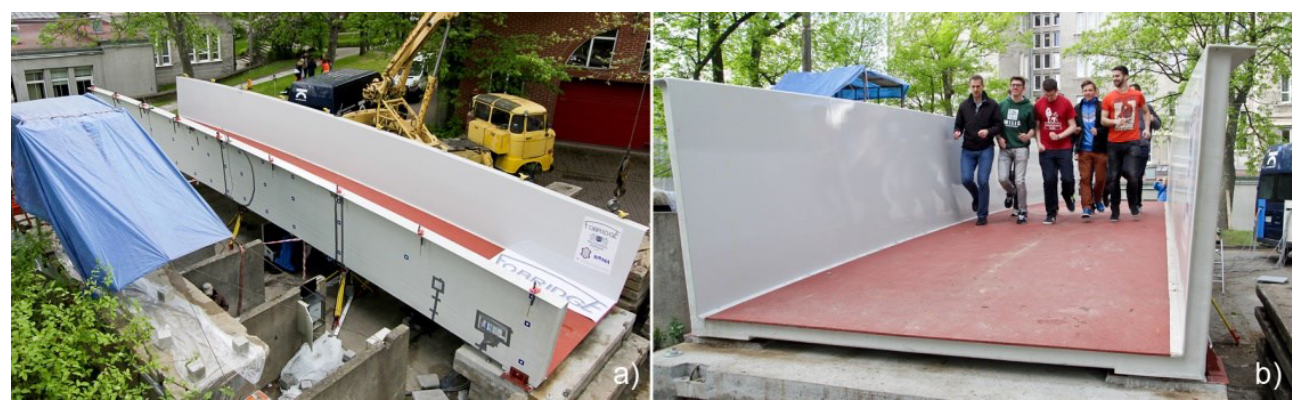

Fig. 8. GFRP footbridge constructed within Fobridge project.

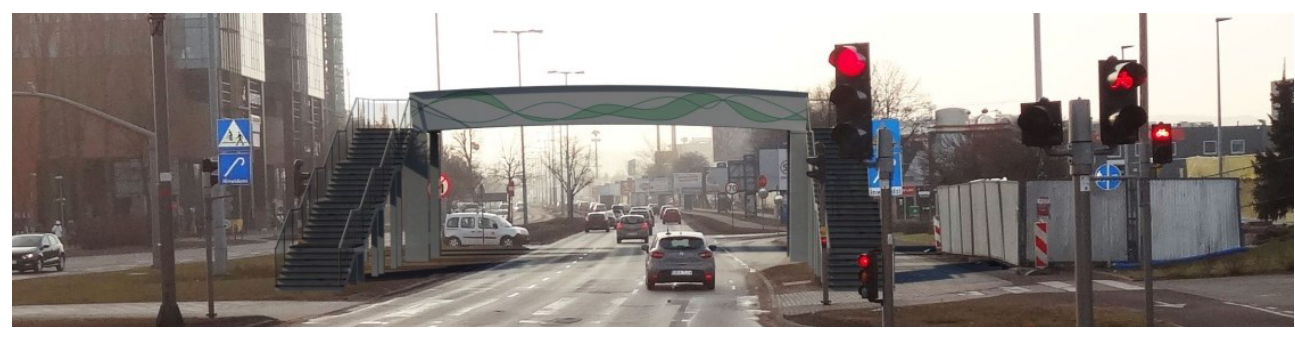

Fig. 9. Visualization of Fobridge GFRP footbridge over a three lane road.

\section{Conclusions}

The principles and criteria for the choice of pedestrian crossing types are described in [3]. The author claims that to reduce the probability of pedestrian accidents the sources of danger related to time and space should be eliminated. This is why traffic lights, asylum islands, footbridges and tunnels must be constructed to move vulnerable road users to a different level than the road. Where justified, pedestrian bridges may be the best or only option available.

The article presents examples of grade separated pedestrian crossings using different types of footbridges. The examples show the variety of forms and the space-making potential of engineering structures [12]. The main advantage of pedestrian footbridges is that they separate pedestrians from road traffic. As a result, footbridges (and stopping pedestrians from crossing the roadway at-grade) may reduce pedestrian accidents up to $90 \%$. The main drawback of collision-free crossings are their costs and their invasive character. The last example of a GFRP structure makes a faster, cheaper and environmentally friendly redesign of the infrastructure possible [9][11]. Lightweight GFRP structures do not need extensive foundations, they are price competitive, do not need expensive maintenance and their manufacture, transportation and installation are much easier and faster compared to steel or concrete solutions.

\section{References}

1. Ranking EU Progress on Road Safety, 10th Road Safety Performance Index Report, available at: http://etsc.eu/wp-content/uploads/10-PIN-annual-report-FINAL.pdf (2016)

2. E. Symon, Road accidents in Poland in 2015. Report of General Police Headquarters of Poland (Warsaw, 2016)

3. K. Jamroz, S. Gaca, L. Michalski, M. Kieć, M. Budzyński, L. Gumińska, W. Kustra, T. Mackun, I. Oskarbska, J. Rychlewska, A. Ryś, J. Wachnicka, J. Wierzbicka, Protection 
of Pedestrians. Guidelines for pedestrian traffic organizers (in Polish) (National Road Safety Council, Gdansk, Warsaw, Cracow, 2014)

4. Regulation of the Minister of Transport and Maritime Economy of 2 March 1999 on technical conditions for public roads and their location, OJ 1999 No. 43 Pos. 430 (Poland, 1999)

5. Regulation of the Minister of Transport and Maritime Economy of 30 May 2000 on technical conditions, which should be ful-filled in case of the road engineering objects and their placement, OJ 2000 No. 63, Pos. 735 (Poland, 2000)

6. M. Malinowski, M. Miśkiewicz, J. Chróścielewski, A. Banaś, Arch footbridge under load testing, Zesz. Nauk. Politech. Rzesz. Bud. I Inżynieria Środowiska. 58 pp. 165$172(2011)$

7. T. Siwowski, A. Wysocki, The circular footbridge in a city center, in: 4th Int. Conf. FOOTBRIDGE, pp. 713-718 (Wroclaw, Poland, 2011)

8. Ł. Pyrzowski, J. Kałuża, M. Miśkiewicz, Ł. Filar, M. Wazowski, K. Wilde, Load tests of arch footbridge 10t over road S8 in Warsaw, in: Wrocławskie Dni Most. Most. Łukowe - Dzieła Kult. Proj. Budowa, Utrzymanie, pp. 419-426 (Wroclaw, Poland, 2015)

9. R. Okraszewska, L. Pyrzowski, M. Miskiewicz, Composite footbridge - synergy effect in cooperation between universities and industry, in: ICERI2014 Proc., pp. 2897-2903 (2014)

10. M. Miskiewicz, L. Pyrzowski, J. Chroscielewski, K. Wilde, Structural health monitoring of composite shell footbridge for its design validation, in: 2016 Balt. Geod. Congr. (BGC Geomatics), pp. 228-233 (IEEE, 2016). doi:10.1109/BGC.Geomatics.2016.48

11. J. Chróścielewski, M. Miśkiewicz, Ł. Pyrzowski, K. Wilde, Composite GFRP UShaped Footbridge, Polish Marit. Res. 24 pp. 25-31 (2017). doi:10.1515/pomr-20170017

12. M. Salamak, K. Fross, Bridges in Urban Planning and Architectural Culture, Procedia Eng. pp. 207-212 (2016) 